Journal of Education and Vocational Research

Vol. 5, No. 3, pp. 119-124, September 2014 (ISSN 2221-2590)

\title{
Conflict Resolution in the Senior High Schools in Ghana and its Implications for Educational Administration: A Case Study of Ashanti Region, Ghana
}

\author{
Ernest Kwabena Gyan ${ }^{1}$, Patrick Tandoh-Offin ${ }^{2 *}$ \\ ${ }^{1}$ Accra Institute of Technology (AIT) With Open University of Malaysia \\ ${ }^{2}$ GIMPA School of Public Service and Governance (GSPSG), Accra, Ghana \\ *ptandoh@gimpa.edu.gh
}

\begin{abstract}
The specific objective of this research is to look at conflict resolution in institution as being experienced in Ghanaian Senior High School. The researcher used descriptive research design to collect data from forty-three (43) Senior High Schools in the Ashanti Region of Ghana. The result indicated that when conflict is managed well, there is performance and better output; increasing effectiveness and efficiency in the school system. Despite limitations of the study, the general results depicted the core role conflict resolution plays in achieving institutional aims, objectives, aspiration and goals
\end{abstract}

Keywords: Senior High School, Single Spine Salary Structure, School Management, Conflict Resolution

\section{Introduction}

Institutional performance depends on either Positive or Negative nature of conflict and how well head teachers and administrators are able to handle. In every organization particularly educational, this helps to increase output Armstrong (2009). If conflict situation is unbearable, it militates against efficiency. For any group or individuals in institutions to be efficient, they need to work in a positive conflict environment. Conflicts well managed improves innovation and creativity in organization, (Murthy, 2006). A research conducted by Bricoe and Schuler (2004) indicated appropriate guidelines for turning dysfunctional conflicts into functional conflicts. Bricoe and Schuler indicated that many institutions use win-lose nature and competitive approach to curb conflict. They indicated that such negative view to conflict breed inefficiency creating destruction to the core purpose of viewing conflict leads to a win-win solution leading to cohesion and healthy competition with institutions. Dysfunctional conflicts, conflict avoidance and functional conflicts being the three main views of conflict could be taken by any member within a group by looking at how and where the institution is aspiring to be. According to (Dowling et al., 2008) top level managers see group conflict as an unfortunate situation and therefore resolve or entirely eliminate all types of disputes. They lamented that these top-level managers have come to accept that conflict actually disorganize activities within an institution thereby preventing optimal performance. Dowling et al. (2008) alerted that if conflict is visible, then there is something wrong and that guidelines are not followed to the maximum in managing activities.

Writers such as Browarys and Price (2008) suggested an approach based on principles of authority and unity of command to curb conflict. They indicated that conflict could be entirely curbed by employing qualified human resource, giving a vivid job description, spelling out a clear chain of command and giving out rules to be followed by all employees and strict guidelines to meet any unforeseen situation which could be internal or external that could affect the institution. Griffin (2006) mentioned that any manager who look at conflict as being disruptive and chaotic spend all their time to eliminate. A proactive manager addresses conflict situation enough, instead of permitting heated difference to develop (Franken \& Wallen, 2000). According to Gupta, (2008) human resource policies provide a strict procedure to enhance good relationship in the working environment, which is vital in curbing conflict. He continues that Human Resource Policies helps to look at vulnerable or susceptible department where conflict could easily erupt such as emoluments of employees, motivation packages and condition of service. This means that the policies should serve as watchdog over activities at all levels within the institution to promote healthy competition, team spirit and feeling of belongingness. Top and middle level managers, policies tackle the procedures in taking decisions and providing standards for control. (There should be adherence to flexibility in using human resource 
policy). The researchers observed that Senior High Schools (SHSs) in Ashanti Region, like most Senior High Schools in Ghana, have for a long time experienced conflicts of a diverse kind. It was important, therefore, to investigate the causes of conflict and to assess the methods which are used for conflict resolution in the SHSs. The researchers were of the opinion that an investigation of this kind can pave the way for improved understanding and resolution of conflict between various actors in schools. A scientific study of conflict in schools can provide data which can be used to make constructive recommendations towards the resolution of conflict.

\section{Literature Review}

According to Adler, (2008) identified two types of conflict to include intergroup conflict and interpersonal conflicts. He indicated that intergroup Conflict arises when goals, task dependency, different work orientation competition for scarce resource and inconsistent reward system become order of the day. He indicated that when Conflict becomes visible, then it must go through certain stages, covering a wide range of behaviour, for example accommodating or avoiding it. This helps to bring about a change which permits within or among groups in the institution. The change has positive as well as negative effect in the institutional performance. Nzuve (2007), view conflict from the same angle as Adler (2008) as he indicated that interpersonal conflict resulting from personality variable such as prejudice and rivalry deter optimum performance in institutions. He indicated that when interpersonal conflict erupts, employees are bet on gaining advantage over others to the detriment of work performance. The nature of conflict could be determined by how it could be managed. He advised managers should always be proactive identify early signs, sources and likely disaster it could cause thereby finding the appropriate strategy to resolve it. Brown (2002) indicated in his book "managing conflict of organizational interface" that, the role of contingency theory recognizes the impact of a given antidote on institutional behaviour patterns leading to absolute conflict resolution. The researchers adopted Muhammed et al. (2009) and Adler (2008) model for the research. This conceptualized model is seen below as Figure 1. The model indicates mechanism where conflict consciousness and its handling strategies impact on institutional performance alongside institutional factors

\section{Figure 1:}

\section{Conceptual model}

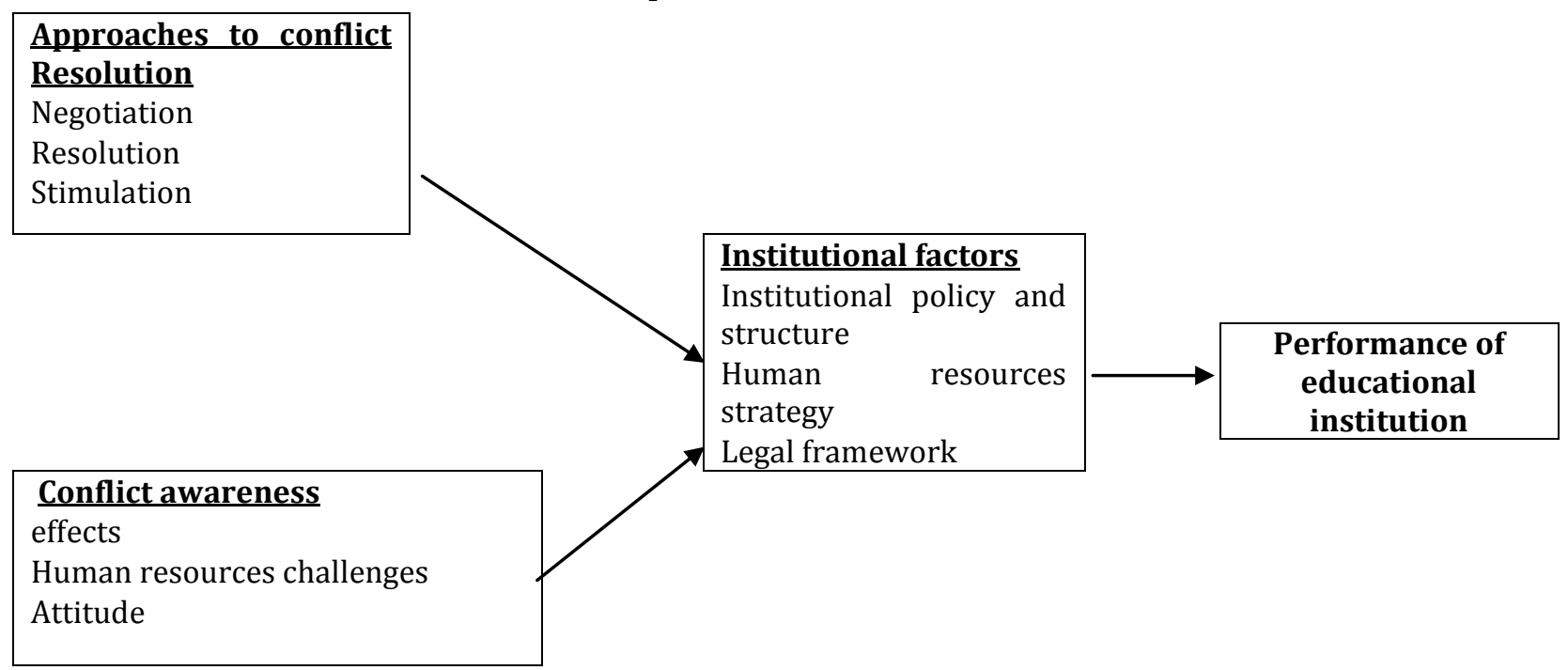

The Literature review revealed that negative effect of conflicts in schools could cause individuals or groups to become hostile and to the point that they could withhold information needed for decision making or resources for school management. It can cause hard working employees to leave the organisation and conflict could also generate detrimental effect for institutional performance among schools. Since conflict is inevitable in organisations, its resolution determines whether it will generate positive or negative effect on institutional performances. The literature review also suggested that some conflicts could generate positive effects for 
groups and organisations which could even lead to improved performance. Such conflicts are regarded as functional and constructive.

\section{Research Methods}

The researcher was collected from Public Senior High Schools in Kumasi in the Ashanti Region of Ghana. The choice of this Region was appropriate since it had experienced the highest occurrence of conflicts among public senior high schools in Ghana. Moreover, given the region's proximity to Kumasi, the Metropolitan Capital City, the diversity of the students' population reflected typical public Senior High Schools in Ghana. The Region has a higher number of schools that admits students from across the Nation and there is greater diversity among the managers heading the schools. It was thus the researcher's opinion that Ashanti region has a fair representation of the country and a region with a greater number of Public Senior High School. A random sample of $43 \mathrm{School}$ heads representing $30 \%$ of the total population of public school in the Ashanti Region was selected for the purpose of the research. The researcher gathered data through the administration of a questionnaire to respondents drawn from various categories or departments of the Senior High Schools set up. The questionnaire required the respondents to give their approaches, attitudes and effects of conflict in their respective secondary schools. They also compared the relationship between the management of conflict and the performance of their school coming up with recommendations for improving conflicts resolution strategies in their respective public secondary schools. It was paramount to find out questionnaire further required them to reflect on the extent of conflict in their respective schools.

The survey instrument was pre-tested to improve its validity and relevance to the objectives of the study. The questionnaires were scrutinized for errors and omissions, ambiguity, legibility and relevance. The questionnaires' content, structure and sequence were appropriately amended to remove any ambiguities and to enhance content validity. Descriptive design was used for the research. According to Orodho (2003), the descriptive design was adopted because descriptive studies are not only useful for fact finding but often result in the formulation of important principles of knowledge and solution to significant problems. Kombo and Trmp (2007) further concluded that wherever possible, a valid conclusion is drawn from facts discussed. The data collected from the respondents was validated, screened and then coded. During the screening and validation process, the questions were checked for accuracy, missing values and errors. After going through all the questionnaires, uniform categories of responses were identified, classified and entered into appropriate categories. According to Swift and Piff (2005), it is imperative that an appropriate analytical technique be adopted that brings out the quantitative meaning of data. In this study, the researcher considered the measurement scale of the variables, nature of data, number of variables involved, relationship between variables and the sample size. Quantitative data was characterized using descriptive statistics to meaningfully describe the distribution of scores. The types of statistics or indices used depended on type of variables in this study and the scale of measurement used that is nominal, interval, ratio and ordinal scales, giving the research a valid and reliable conclusions for recommendation.

\section{Results}

Strategies used in Conflict Resolution: The research sought to identify the common but popular conflict resolution techniques among the selected school administrator. Table 1 presents a summary of the findings. The researcher found that $92.7 \%$ (i.e. 38 out of 41 ) of the respondents used stimulation techniques to resolve conflicts in their schools. Such strategies included transferring of individual with diverged views, suspension or expulsion, and use of incentives to suppress conflict. The researcher found this very unfortunate as this offered only a short term solution to the problem. This approach though in wide usage is very unstable in the long term.

Table 1

\begin{tabular}{lll}
\hline Strategies & Frequency & Percent \\
\hline Resolution & 17 & 41.5 \\
Negotiation & 16 & 39.1 \\
Stimulation & 38 & 92.7 \\
\hline
\end{tabular}


The findings further indicated that $41.5 \%$ of the respondents employed resolution techniques to manage conflict. Such a process is all-inclusive and the personnel feel that their contribution to the solution of a conflict is acknowledged. In addition, $39.1 \%$ of the respondents reported frequently or always negotiating with staff to reach a compromise. Thirty-nine percent (39\%) of the respondents used negotiation techniques strategies. The study findings indicated that 20 (49.7\%) of the study respondents or never used collaborative process in order to have joint gains with their personnel. Most of the study respondents were non-committal with regard to use of an all-inclusive negotiates strategies as conflict handling techniques. For example, it is important to note that 13 representing $(31,7 \%)$ of the respondents said that they always used splitting the difference (putting to vote) when there is an impasse in any conflict. In fact, 9 representing $(21.7 \%)$ admitted that they frequently used splitting the difference when an impasse arises. This is an escape route and its benefits are always short-lived. The most famous approach is stimulation with (92.7\%).This indicate that respondents are used to this conflict resolution techniques in schools. Some approaches to conflicts resolution may promote a search for resolutions whereas others may lead to deadlock. For example, selfawareness and care are essential to an effective approach to conflict management. The more one is aware of his/her own biases and "hot buttons," the more likely one is prepared mentally, emotionally and physically to respond in a preferred way to any conflict in an educational institution.

Challenges facing Human Resource in Resolving Conflict: Having investigated the use of conflict resolution in schools, the researcher went further to determine the human resources challenges experienced in schools. Peer influence and absenteeism in table 2 was reported to be a major challenge in most schools. Peer influence was also reported to be a major contributor (82.9\%) of conflicts within schools. Peer influence appeared to be linked to other problems associated with conflicts in schools.

Table 2: Human resource challenges in schools

\begin{tabular}{lll}
\hline Problem Encountered & Frequency & Percent \\
\hline Drug abuse & 23 & 56.1 \\
Rudeness & 30 & 73.2 \\
Dissatisfaction & 27 & 65.9 \\
Peer group influence & 34 & 82.9 \\
Stealing & 29 & 70.7 \\
Drunkenness & 16 & 46.3 \\
Insubordination & 25 & 60.9 \\
Absenteeism & 38 & 92.7 \\
Friction and infighting & 30 & 73.2 \\
\hline
\end{tabular}

The findings shown in table 3 depicts that suspension and expulsion are seen to be the most common forms of disciplinary action employed by school heads in dealing with cases of indiscipline and conflict. The use of corporal punishment together with Guidance and counseling were averagely popular that the school administration used but the use of experts was not as popular when dealing with indiscipline.

Table 3: Strategies applied to deal with indiscipline in schools

\begin{tabular}{lll}
\hline Disciplinary measure & Frequency & Percent \\
\hline Use of Experts & 11 & 26.8 \\
Use disciplinary committee & 31 & 75.6 \\
Guidance \& counseling & 27 & 65.9 \\
Expulsion or sacks & 34 & 82.9 \\
Suspension & 38 & 92.7 \\
Use corporal punishment & 27 & 65.9 \\
\hline
\end{tabular}

Table 4 below is the frequency distribution of respondents indicating capacity to deal with conflicts. The results indicate that the capacity to deal with conflict situations in schools is quite low and raise concern among Ghanaian education policy makers in order to minimize conflicts within schools. 
Table 4: Capacity to deal with conflict in schools

\begin{tabular}{lll}
\hline Capacity & Frequency & Percent \\
\hline Industrial relation policies & 10 & 24.4 \\
Personnel development policies & 8 & 19.5 \\
Trained personnel in conflict resolution & 8 & 19.5 \\
Resources and sourcing policies & 8 & 19.5 \\
Allocation and delegation of duties & 10 & 24.4 \\
Conflict resolution policies & 8 & 19.5 \\
Hiring and firing policies & 7 & 17.1 \\
Management policies & 12 & 29.3 \\
Compensation and rewarding structures & 10 & 24.4 \\
\hline
\end{tabular}

The results from school manages indicated that various groups within the school community required attention in order to manage conflicts within and across the groups. The level of attention needed differ and table 5 presents a summary of the results.

Table 5: School- community members need for attention

\begin{tabular}{lll}
\hline Require a lot of attention & Frequency & Percent \\
\hline Teaching staff & 25 & 61.0 \\
Non- teaching staff & 15 & 36.6 \\
Students representative council & 19 & 95.1 \\
\hline
\end{tabular}

Attitude of the school managers towards Conflict Resolution: One of the researcher's objectives in carrying out this research was to unearth school heads' attitude towards conflict resolution. They discovered that $93 \%$ of the schools had experienced some form of conflict in the past. Most of these were negative conflicts. The researcher also found that most of the school heads were unaware that conflict can be positive and consequently had a very negative attitude towards conflict at the work place. However, a majority (78\%) of the heads acknowledged the need to resolve conflicts amicably in order to improve organizational performance. Research has also shown that task related conflict could be beneficial to the institution when ideas are exchanged amongst the group members (Ford, 2007). Again, benefits include improved group learning and enhanced accuracy in assessment situation (Jones et al., 2000). Development of new ideas (Adomi \& Anie, 2005) and better quality decisions (Simons \& Peterson, 2000). Conflict could be seen as productive force that could improve institutions and contribute to creativity and innovation in the institution

Recommendations for Enhancing Conflict Resolution in Senior High School: The school administration role dealing with conflict cannot be underestimated. The study investigated the school heads on the kind of strategies they would prefer in order to resolve and manage conflicts within their school. Below reveals some of the more popular recommendations proposed by the respondents.

- More efforts should be put in conflict reduction through education. Training of trainer's workshop should be conducted so as to empower School Administrators, SRC, House Masters, Bursers, and Heads of Departments to educate their peers on conflict reduction and even act as mediators should conflict arise in their departments.

- Proper guidelines of conflict resolution should be put in place in the senior high schools so that when there is conflict; one knows who to report what to and what steps to take to seek resolution.

- There should be proper communication in the schools. The SRC should be involved in the decision making process so that when say there is an increase in school fees, the SRC can educate their colleagues on the rationale behind that or can easily explain in simple terms the policies of the school to reduce unnecessary tension between school administrators and students.

- As a school administrator you must be fair and firm, assign duties on merit, be open in administration, respect views of others in decision making process, encourage teamwork, let everybody feel important, be tactful in difficult situation, recognize and show appreciation. Moreover, school administrators should always keep in mind the five (5) steps in conflict management process; assessment, acknowledgement, attitude, action and evaluation. 


\section{Conclusion}

Should school managers view conflict from a positive angle, then it would be possible to curb these conflicts to improve teamwork, loyalty, cohesion and productivity within Ghanaian Senior High Schools. The building of such synergy and cohesion among school community requires ability to diagnose and resolve the conflicts in their infant stages before they blow out of proportion. School managers should be encouraged to be proactive and sensitive to sources of conflict and be well prepared to deal with conflict situations. As illustrated in the recommendation, communication and training in conflict resolution is essential ingredient in efficient and effective management of conflicts. When a school opens up communication channels and appropriate leadership training provided, conflicts situations can be productive and be prevented from degenerating into unmanageable, full-blown conflicts that destroys life, property and unity among the school administrators, teachers, students, parents and the community.

\section{References}

Advisory, conciliation and Arbitration Service. (2004). Discipline at work: ACAS Advisory Handbook I, London ACAS.

Adomi, E. E. \& Anie, S. O. (2005). Conflict management in Nigeria University. Journal of Library Management, 2, 520-530.

Armstrong, M. (2009). A Handbook of Personnel Management Practice, $10^{\text {th }}$ Ed. Kogon Page Limited, London.

Adler, N. J. (2008). International dimension of organizational behavior, $5^{\text {th }}$ Ed. Mason, Thomson southern Western.

Bricoe, D. R. \& Schuler, R. S. (2004). International human resource management. $2^{\text {nd }}$ edition. Routledge, London.

Brown, L. D. (2002). Managing conflict of organizational interface. Addition-Wesley Publishers, Massachusetts.

Browarys, M. \& Price, R. (2008). Understanding cross cultural management, Pearson Education, Harlow.

Beardwell, J. \& Claydon, T. (2007). Human Resource Management. A contemporary Approach. Pearson Education, Harlow.

Dowling, P. J., Festing, M. \& Engle, A. D. (2008). International Human Resource Management $5^{\text {th }}$ edition. Thomson Learning London.

Gupta, C. B. (2008). Human Resource Management. $9^{\text {th }}$ Ed. Sultan Chand \& Sons, New Delhi.

Griffin, W. R. (2006). Management. AITBS publishers. India.

Ford, J. (2007). Organisational conflict management. www.mediate .com/friendly. Cfm? Id=1250.

Franken, J. R. \& Wallen, N. E. (2000). How to Design and Evaluate Research in Education. McGraw Hill, London.

Jones, G. R., Gorge, J. M. \& Hill, C. W. I. (2000). Contemporary Management. McGraw-Hill, Boston.

Kombo, D. K. \& Tromp. D. L. A. (2007). Proposal and Thesis Writing-An introduction. Kenya: Paulines publications Africa of Financial Institutions. European Journal of scientific Research, 27(4), 479-487.

Murthy, R. P. (2006). Management Science and Industrial Management. Pragon International Publishers, New Delhi.

Muhammed, A. K., Hassan, A. \& Kashif, R. (2009). Impact of Task conflict on Employee's performance.

Ministry of Education. (2008). Report on school Unrest, Ghana.

Nzuve, N. M. S. (2007). Management of Human Resources: A Kenyan perspective. $3^{\text {rd }}$ Ed. Tech \& Bro Associates Publishers.

Orodho, A. J. (2003). Essentials of educational and Social Sciences Research Method. Mazola Publishers.

Swift, L. \& Piff, S. (2005). Quantitative methods for Business Management and Finance. 2nd edition Macmillan, Palgrave.

Simons, T. I. \& Peterson, R. S. (2000). Task conflict and Relationship Conflict on Top management teams; The Pivotal Role of Intra-group trust. Journal of Applied Psychology, 85(14), 109-111. 